\title{
Pododermatitis interdigital en ovinos en condiciones de trópico alto
}

\author{
Foot rot in sheep in tropical conditions
}

\section{Pododermatite interdigital em ovinos em condições tropicais}

\author{
Sandoval Romero Leydy Liceth ${ }^{1}$, Góngora Orjuela Agustín ${ }^{2}$ y \\ Vargas Duarte Jimmy Jolman ${ }^{3}$ \\ ${ }^{1} \mathrm{MVZ}$, Universidad de los Llanos, ${ }^{2} \mathrm{MV}$, MSc, PhD, Docente Universidad de los \\ Llanos y ${ }^{3} \mathrm{MV}, \mathrm{MSc}, \mathrm{PhD}$, Docente Universidad Nacional de Colombia \\ agongora@unillanos.edu.co
}

Recibido 04 de Diciembre 2017, Aceptado 30 de Abril 2018

\section{RESUMEN}

La pododermatitis interdigital es una de las enfermedades pódales más frecuentes en los ovinos y caprinos, se trata de una infección que involucra la piel del espacio interdigital y de la lámina sensitiva de la pezuña causando dolor y por lo tanto claudicación; es ocasionada principalmente por la sinergia de las bacterias anaerobias Dichelobacter nodosus y Fusobacterium necrophorum. La severidad de la enfermedad es dependiente de la naturaleza particular de la cepa, condiciones ambientales como humedad, y temperaturas superiores a $10{ }^{\circ} \mathrm{C}$ son esenciales para la transmisión de la enfermedad, la cual tiene un gran impacto económico en la producción ovina mundial. El objetivo de este trabajo fue evaluar, clasificar y controlar los diferentes grados de afección en el Centro de Investigación, Desarrollo Tecnológico y Extensión Ovino (CIDTEO), e implementar un sistema de pediluvios con sulfato de zinc al $10 \%$ en la población para posteriormente realizar registro de evolución y respuesta al tratamiento, para ello se realizó la evaluación clínica de la enfermedad durante cuatro meses a 263 animales; para evaluar la efectividad del tratamiento se tomó como grupo experimental 16 corderos de diez meses de edad, de los cuales ocho eran animales criollos y el resto de raza Corriedale, los animales fueron divididos en dos grupos (control y tratamiento), y cinco días post tratamiento se evaluó la efectividad del sulfato de zinc al $10 \%$ mediante registro fotográfico. La prevalencia 
de la enfermedad en el rebaño fue $22.43 \%$, de los cuales el $2.14 \%$ de pezuñas fueron afectadas en un grado avanzado o severo, donde generalmente se diagnostican microorganismos con alta virulencia; los animales criollos resultaron más afectados que los de raza pura. En cuanto a la efectividad del tratamiento, con sulfato de zinc al $10 \%$ en pediluvio se pudo recuperar el $97 \%$ de las pezuñas afectadas, por lo cual se concluye que el tratamiento es efectivo para el control de la pododermatitis interdigital, además los factores medioambientales juegan un papel importante en el desarrollo y evolución de la enfermedad.

Palabras clave: Podología, pezuñas, pequeños rumiantes, claudicación, prevención.

\section{ABSTRACT}

The foot rot is one of the most frequent podal diseases in sheep and goats, it is an infection that involves the skin of the interdigital space and the sensitive lamina of the hoof causing pain and therefore claudication; is caused mainly by the synergy of the anaerobic bacteria Dichelobacter nodosus and Fusobacterium necrophorum. The severity of the disease is dependent on the particular nature of the strain, environmental conditions such as humidity, and temperatures above $10{ }^{\circ} \mathrm{C}$ are essential for the transmission of the disease, which has a great economic impact on world sheep production. The objective of this work was to evaluate, classify and control the different degrees of affection in the Center for Research, Technological Development and Ovine Extension (CIDTEO), and implement a system of footbaths with $10 \%$ zinc sulphate in the population to subsequently record progress and response to treatment, for this, the clinical evaluation of the disease was carried out for four months in 263 animals; To evaluate the effectiveness of the treatment, 16 lambs ten months old were taken as an experimental group, of which eight were creole animals and the rest Corriedale, the animals were divided into two groups (control and treatment), and five days after treatment the effectiveness of zinc sulfate at $10 \%$ was evaluated by photographic record. The prevalence of the disease in the herd was $22.43 \%$, of which $2.14 \%$ of hooves were affected in an advanced or severe degree, where microorganisms with high virulence are usually 
diagnosed; creole animals were more affected than purebred animals. Regarding the effectiveness of the treatment, with $10 \%$ zinc sulphate in the footbath, $97 \%$ of the affected hooves could be recovered, for which it is concluded that the treatment is effective for the control of foot rot, in addition, environmental factors play an important role in the development and evolution of the disease.

Keywords: Podiatry, hooves, small ruminants, claudication, prevention.

\section{RESUMO}

A pododermatite interdigital é uma das doenças podais mais freqüentes em ovinos e caprinos, é uma infecção que envolve a pele do espaço interdigital e a lâmina sensível do casco causando dor e, portanto, claudicação; é causada principalmente pela sinergia das bactérias anaeróbias Dichelobacter nodosus e Fusobacterium necrophorum. A gravidade da doença depende da natureza particular da cepa, condições ambientais como umidade e temperaturas acima de $10^{\circ} \mathrm{C}$ são essenciais para a transmissão da doença, que tem grande impacto econômico na produção mundial de ovinos. O objetivo deste trabalho foi avaliar, classificar e controlar os diferentes graus de afeto no Centro de Pesquisa, Desenvolvimento Tecnológico e Extensão de Ovinos (CIDTEO), e implementar um sistema de pedilúvio com $10 \%$ de sulfato de zinco na população para subsequentemente registrar o progresso e a resposta ao tratamento, para isso, a avaliação clínica da doença foi realizada por quatro meses em 263 animais; Para avaliar a eficácia do tratamento, 16 cordeiros com dez meses de idade foram tomados como grupo experimental, dos quais oito eram animais crioulos e o resto Corriedale, os animais foram divididos em dois grupos (controle e tratamento) e, cinco dias após o tratamento, a eficácia do sulfato de zinco a $10 \%$ foi avaliada por registro fotográfico. A prevalência da doença no rebanho foi de $22,43 \%$, dos quais $2,14 \%$ dos cascos foram afetados em grau avançado ou severo, onde microrganismos com alta virulência geralmente são diagnosticados; os animais crioulos foram mais afetados que os animais de raça pura. Quanto à eficácia do tratamento, com $10 \%$ de sulfato de zinco no pedilúvio, $97 \%$ dos cascos afetados puderam ser recuperados, para os quais se conclui que o tratamento é eficaz para 
o controle da pododermatite interdigital, além disso, fatores ambientais desempenham um papel importante no desenvolvimento e evolução da doença.

Palavras-chave: Podologia, cascos, pequenos ruminantes, claudicação, prevenção.

\section{INTRODUCCIÓN}

La ovinocultura en Colombia ha dejado de ser una actividad artesanal y se está posicionando como una nueva industria en el país; dentro de los principales departamentos que proveen carne ovina y han llevado un mayor desarrollo de la producción se encuentran la Guajira, Cesar, Magdalena y Santander, sin dejar a un lado el centro y occidente del país. Colombia continúa con una población ovina fluctuante en alrededor de dos millones de cabezas desde el 2005 (Arévalo y Correa, 2013). Es por ello la importancia de implementar estrategias que permitan mejorar la producción ovina desde el punto de vista nutricional, genética, reproductiva y sanitaria, en este último destacando planes de salud preventiva, para garantizar una producción limpia y competitiva tanto en mercados nacionales como internacionales.

Los ovinos son pequeños rumiantes que a lo largo del tiempo se han provisto carne y leche de excelente calidad, se destacan además por su capacidad para reproducirse en poco tiempo e incrementar su población (Hernández, 2012), por lo cual una mala estrategia o implementación de plan sanitario, genera pérdidas económicas atribuida a enfermedades pódales y parasitarias. La pododermatitis interdigital es una enfermedad infecto-contagiosa crónica de los ovinos, caprinos y bovinos, que generalmente se incrementa con la edad (da Silva, 2016). Esta afección está confinada al tejido epidérmico del espacio interdigital de la piel y la pezuña. Los factores predisponentes más importantes para la transmisión son la humedad, calor y lesiones del pie; las principales pérdidas directamente atribuidas a la pododermatitis en ovinos se manifiestan en la producción de carne, lana y aumento de la prevalencia de miasis (Mederos et al., 2001). 
La pododermatitis infecciosa o footrot es una de las enfermedades pódales más frecuentes entre ovinos y caprinos, que involucra la piel del espacio interdigital y de la lámina sensitiva de la pezuña, ocasionando claudicación severa y prolongada, causada por dos bacterias que actúan de forma sinérgica, Fusobacterium necrophorum y Dichelobacter nodosus (Bennett, 2011); la severidad de la enfermedad depende de la naturaleza particular de la cepa y de las condiciones ambientales como la humedad y temperatura (Kennan et al., 2011). La etiología puede ser determinada por otros factores como la genética del hospedero, inmunidad adquirida del rumiante, prácticas de manejo en la granja y factores ambientales (Bennett, 2011). El principal agente causal de la putrefacción del pie ovino es $D$. nodosus, que es una bacteria anaerobia obligatoria gram negativa (Cederlöf et al., 2013), que también trabaja en sinergia con $F$. necrophorum, gram negativa no esporulada, con la capacidad de producir hemolisinas, leucotoxinas, proteasas, lipasas, y adesinas (Bennett, 2011).

La presentación de la enfermedad se caracteriza por la apariencia de exudado inflamatorio y necrosis del tejido epidermal de la pezuña, cuya severidad varía según la forma de presentación: pododermatitis interdigital leve, intermedia y severa. La primera presenta signos de inflamación, ulceración y material necrótico húmedo en piel interdigital, pero no progresa a forma severa donde hay destrucción del casco (Kennan et al., 2011); en la segunda se empieza a afectar la pezuña, y se puede determinar comparando las afecciones con los animales del rebaño, y en la tercera se observa destrucción de la queratina, erosión y desprendimiento de la pezuña, llega a ser altamente contagiosa, con olor nauseabundo, por la descomposición de la queratina que es rica en azufre (Bennett, 2011).

Esta enfermedad comienza con una dermatitis interdigital (DI), ocasionada por $D$. nodosus, que está presente antes de que se desarrolle una pododermatitis severa, el microorganismo invaden estructuras epidérmicas ocasionando cojeras y finalizando en algunos casos con laminitis y desprendimiento del casco (Witcomb et al., 2015), además se ha encontrado que este patógeno puede sobrevivir en el 
suelo con células viables detectadas hasta en el día 40 (Muzafar et al., 2016); aunque muchos de los casos inician con una proliferación previa de la bacteria $F$. necrophorum, lo que desarrolla una típica lesión de la pezuña que facilita la invasión epidérmica de $D$. nodosus. En clima cálido y húmedo el periodo de incubación va de 5 a 7 días, el organismo invade los tejidos blandos, ocasionando tumefacción aguda y posteriormente necrosis, propagándose a vainas tendinosas e incluso llegando al hueso (da Silva, 2016), los signos o lesiones se pueden detectar por medio de una ligera cojera de una o más extremidades, que empeora de forma rápida, aunque inicialmente solo se observa inflamación de la piel en el espacio interdigital, después la pezuña muestra diversos grados de deformación, muerte y desprendimiento de tejidos, en casos avanzados el animal no apoya el miembro o permanece inmóvil. El diagnóstico de esta enfermedad se realiza mediante inspección de cada una de las pezuñas, siguiendo la escala de clasificación planteada por (Webb y Kluver, 2014), la cual va de 1 a 5 , donde 1 es leve y 5 es grave (Tabla 1 ).

Tabla 1. Clasificación grados de pododermatitis interdigital

\begin{tabular}{|c|c|}
\hline Puntaje & Descripción \\
\hline 1 & $\begin{array}{l}\text { Dermatitis interdigital la cual implica una inflamación y erosión de la } \\
\text { capa superficial de la piel, entre los dedos del animal. }\end{array}$ \\
\hline 2 & $\begin{array}{l}\text { Dermatitis interdigital más extensa, con una inflamación severa de la } \\
\text { pared interior de la pezuña, comprometiendo la dermis interdigital de } \\
\text { los talones. }\end{array}$ \\
\hline $3 a$ & $\begin{array}{l}\text { Separación de la piel de los talones extendiéndose hacia lo alto de la } \\
\text { pezuña (muralla) no más de } 5 \mathrm{~mm} \text {. }\end{array}$ \\
\hline $3 b$ & $\begin{array}{l}\text { Separación de la piel exterior del talón, dispersándose a través de la } \\
\text { suela un poco más que el score } 3 a \text {. }\end{array}$ \\
\hline $3 c$ & $\begin{array}{l}\text { Amplia separación del talón, sin extenderse hasta el borde exterior } \\
\text { de la suela del pie. }\end{array}$ \\
\hline 4 & $\begin{array}{l}\text { Comprometida toda la suela, con una separación de las paredes y el } \\
\text { borde exterior de la planta. }\end{array}$ \\
\hline 5 & $\begin{array}{l}\text { Necrosis del tejido más profundo de la pared exterior, con la } \\
\text { consiguiente separación de toda la muralla de la pezuña. }\end{array}$ \\
\hline
\end{tabular}

Fuente: Webb y Kluver, (2014). 
Para el tratamiento y prevención de esta enfermedad se debe tener en cuenta las condiciones en las que los animales se encuentran, como el clima, humedad y alimentación; posteriormente se realiza un análisis de las posibles causas, con el fin de disminuir el impacto que generan, porque estas enfermedades pódales causan pérdidas económicas en la producción; una vez realizado el análisis se hacen registros de la clasificación de la pododermatitis interdigital de todo el rebaño, luego de estas acciones se da comienzo al despezuñado con corte, limpieza, y aplicación de agua oxigenada o azul de metileno; para ello las herramientas usadas deben estar desinfectadas para su uso en cada animal, con el fin de evitar contaminación cruzada, posteriormente los animales son llevados a un pediluvio con sulfato de zinc al $10 \%$ por 15 minutos.

Es importante señalar que los pediluvios son necesarios para fines preventivos y curativos en la lucha contra la enfermedad, por ello toda explotación debe contar con instalaciones para realizarlos de forma cómoda y eficaz (Fernández et al., 1996); se utiliza sulfato de zinc para baños pódales para el tratamiento de pezuñas en ovinos y bovinos, por su capacidad antiséptica y de penetración en los tejidos, además no es irritante, se recomienda el uso de este agente químico al $10 \%$, el tiempo de mantenimiento en el pediluvio depende del estado de la infección del rebaño. Otros productos que se usan en los baños pódales son formalina y sulfato cobre (Winter, 2011), en general se recomienda las siguientes concentraciones y preparación para cada caso.

Tabla 2. Soluciones usadas en baños pódales

\begin{tabular}{|c|c|}
\hline Sustancia & Descripción \\
\hline Sulfato de cobre & $\begin{array}{l}\text { Solución al 3-5\%, agregar de } 3 \text { a } 5 \text { libras de sulfato de } \\
\text { cobre con } 12.5 \text { galones de agua. Usar durante } 15 \\
\text { minutos y dejar secar por } 1 \text { hora en concreto, se puede } \\
\text { repetir cada } 1 \text { o } 2 \text { semanas. }\end{array}$ \\
\hline Formaldehído & $\begin{array}{l}\text { Solución de formalina al } 3-5 \% \text {, considerado un químico } \\
\text { peligroso de daño potencial para humanos. }\end{array}$ \\
\hline Sulfato de zinc & $\begin{array}{l}\text { Solución de sulfato de zinc al } 5-10 \% \text {, agregar de } 5 \text { a } 10 \\
\text { libras de sulfato de zinc a } 12.5 \text { galones de agua, } \\
\text { tratamiento de } 5-7 \text { días durante } 15 \text { minutos. }\end{array}$ \\
\hline
\end{tabular}




\section{METODOLOGÍA}

Este trabajo se realizó en el Centro Agropecuario Marengo y Centro de Investigación, Desarrollo Tecnológico y Extensión ovino - CIDTEO, ubicado en el centro agropecuario Marengo, en el kilómetro 14 vía al municipio de Mosquera, Departamento de Cundinamarca, con una temperatura promedio de $13.6^{\circ} \mathrm{C}$, humedad relativa del $51 \%$ y precipitaciones de $649 \mathrm{~mm}$ al año.

La fase de campo se llevó a cabo con el fin de probar la efectividad de un sistema de pediluvio, primero se realizó una inspección total de pezuñas de los animales de la granja; las evaluaciones clínicas de la enfermedad se llevaron a cabo durante cuatro meses, utilizando la escala (1-5) propuesta por Webb y Kluver, (2014). Se utilizaron 16 corderos como grupo experimental de diez meses de edad de los cuales ocho correspondían a la raza criolla colombiana y la otra mitad a la Corriedale, los animales fueron manejados en las mismas condiciones de alimentación, suplementación con sal mineralizada, pastoreo y agua ad libitum; el grupo fue tratado con sulfato de zinc al $10 \%$ en pediluvios, con el fin de evaluar su efectividad con relación al testigo, por lo tanto se procedió a dividir los animales en dos grupos: control y tratamiento, el tratamiento fue sometido a pediluvios sin arreglo podal con sulfato de zinc al $10 \%$ por tres días, mientras que el grupo control continuó en el mismo potrero sin arreglo podal y sin pediluvio: pasados cinco días post tratamiento se evaluó la efectividad del sulfato de zinc al $10 \%$ mediante registro fotográfico comparándolos con los ovinos que no recibieron ningún tratamiento.

Con el objetivo de caracterizar cada lesión y grado de severidad (Tablas 1 y 3 ) del grupo que recibió de tratamiento se realizó inspección detallada de las pezuñas, en donde se evaluó ciertas estructuras anatómicas observándolas de la siguiente forma:

1) Deformidad en el casco. 2) Separación del rodete coronario con el casco, laceraciones, dermatitis o inflamación. 3) Separación de la muralla del casco (cm), alteraciones en su estructura como (discontinuidad, deformidad). 4) Espacio 
interdigital, si hay resequedad, enrojecimiento leve o moderado. 5) Presencia de exudado blanquecino en el espacio interdigital extendiéndose al talón. 6) Inoloro, maloliente, o fétido pestilente, penetrante, fuerte, $\mathrm{u}$ olor nauseabundo de la materia orgánica en descomposición. 7) Observación en el talón desprendimiento de capa cornea y medida de su tamaño $(\mathrm{cm})$. 8) Evaluación de la suela, sí mantiene la integridad de su estructura cornea, presencia de material necrótico, descamación o daño de la estructura con supuración del tejido compromete un tercio de toda la suela. Las evidencias de las lesiones halladas el día cero antes de iniciar el tratamiento se observan en las Figuras 1, 2 y 3.
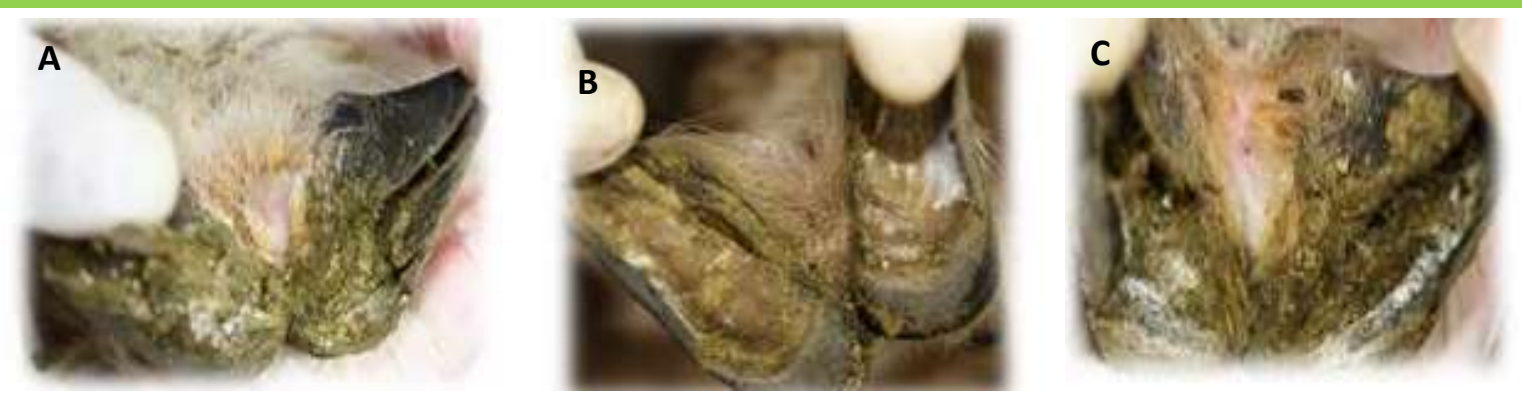

Figura 1. Grado cero: Muralla, talón y suela sin alteraciones (A). Grado 1: Leve crecimiento y enrojecimiento de la muralla, talón y suela sin alteraciones (B). Grado 2: Enrojecimiento moderado y se observa exudado blanquecino (C).
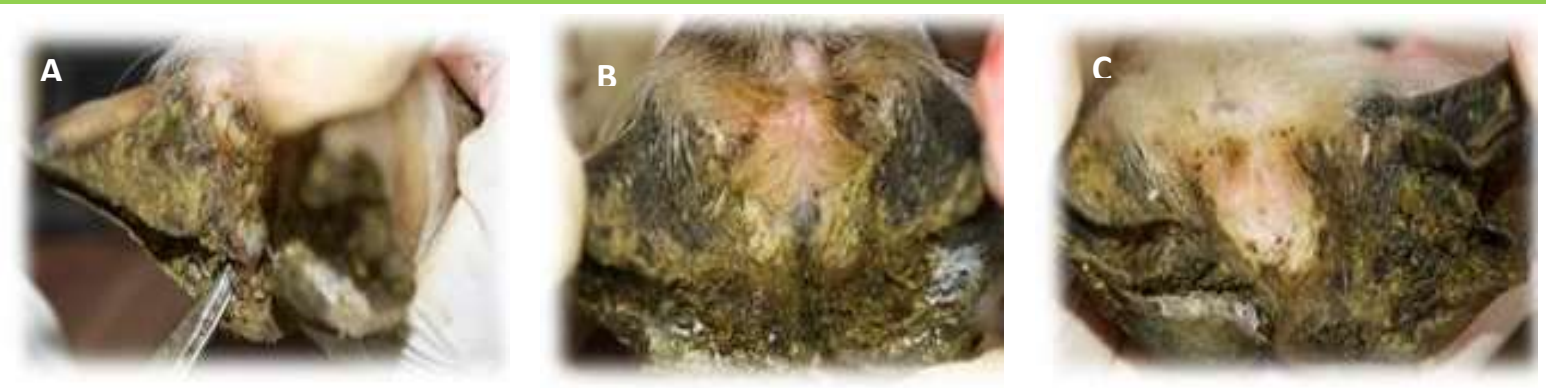

Figura 2. Grado 3a: Muralla con ondulaciones, enrojecimiento moderado y exudado (A). Grado 3b: Muralla con ondulaciones marcadas, enrojecimiento y exudado que se extiende al talón, el cual está desprendido $5 \mathrm{~cm}(\mathrm{~B})$. Grado 3c:

Desprendimiento de la muralla un $\mathrm{cm}$, ondulaciones bien marcadas, enrojecimiento y exudado blanquecino que se extiende, talón desprendido, suela en un $5 \mathrm{~cm}, 50 \%$ con material supurativo y maloliente (C). 


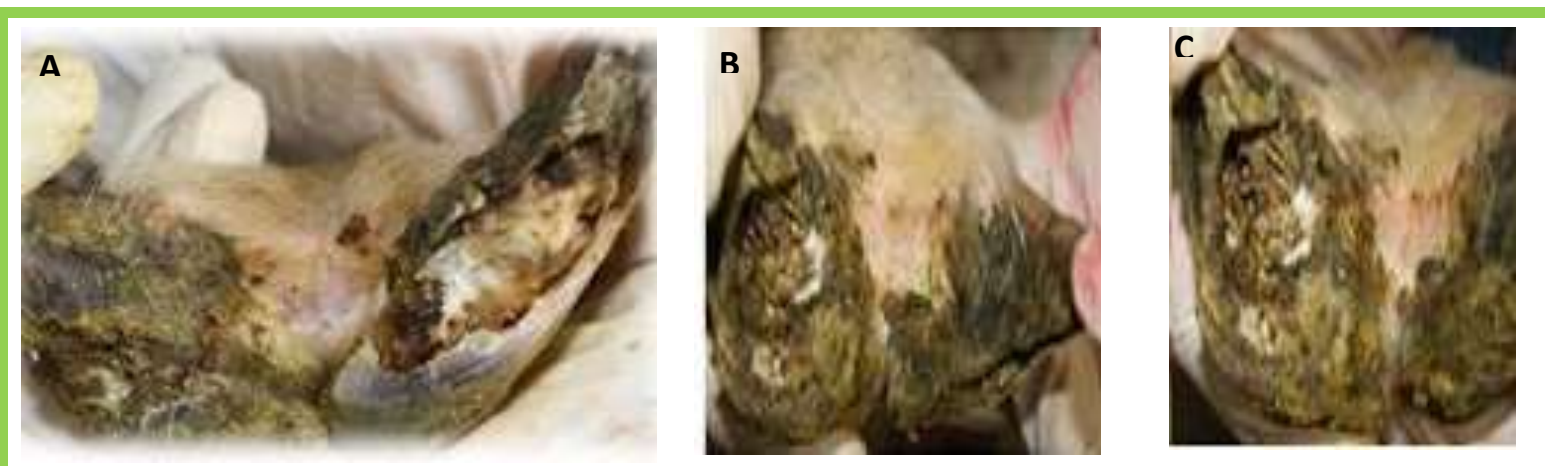

Figura 3. Grado 4: Igual que el grado 3c pero la totalidad de la suela está comprometida con material supurativo blanquecino con olor fétido (A). Grado 5: Igual que el grado 4 pero hay desprendimiento de la muralla (B y $C$ ).

Después de divididos los animales, se realizó una clasificación según la severidad de la pododermatitis interdigital (Tabla 3), los animales 1 a 8 , corresponden a la raza Corriedale y la 9 a 16 a la raza criolla Colombiana; se puede observar que hay variedad en cuanto a la raza, en la forma de presentación de la enfermedad, afectando indiscriminadamente las dos razas, es decir que los factores ambientales y la alimentación juegan un papel muy importante en la predisposición para presentar la enfermedad, aunque se ha observado que los animales de la raza Corriedale son más resistentes, pero no está exenta de la enfermedad, por el contrario la raza criolla Colombiana es más susceptible al padecimiento de la pododermatitis interdigital.

\section{RESULTADOS Y DISCUSIÓN}

En la evaluación clínica de la enfermedad de 1052 pezuñas se encontró que el $22.43 \%$ de los animales (263) estaban afectados frente al $77.57 \%$ (816) que se encontraban sanos, los grupos etarios más afectados fueron las hembras servidas con $7.98 \%$ (84) seguida por las borregas con $4.07 \%$ (43) mientras que los menos afectados fueron los borregos de seis meses de edad $0.29 \%$ (3) y destetos $1.71 \%$ (18) (Tabla 4). 
Tabla 3. Clasificación de la severidad de la pododermatitis interdigital en los animales experimentales

\begin{tabular}{ccccc}
\hline Animal & MAD & MAI & MPD & MPI \\
\hline 1 & 4 & 1 & $3 c$ & $3 a$ \\
2 & 1 & 0 & 0 & 0 \\
3 & 0 & 0 & 1 & 1 \\
4 & 1 & $3 a$ & $3 a$ & $3 a$ \\
5 & $3 b$ & 0 & 1 & $3 c$ \\
6 & 1 & $3 a$ & $3 c$ & 1 \\
7 & 0 & 0 & 1 & 1 \\
8 & $3 a$ & 0 & 0 & 1 \\
9 & 4 & $3 c$ & $3 a$ & 4 \\
10 & 0 & 0 & $3 b$ & 4 \\
11 & 0 & 1 & 1 & 1 \\
12 & 2 & $3 a$ & 1 & $3 a$ \\
13 & $3 a$ & $3 a$ & $3 a$ & $3 a$ \\
14 & $3 a$ & $3 c$ & 2 & $3 c$ \\
15 & 1 & 1 & $3 a$ & 4 \\
16 & 0 & 2 & 0 & 0 \\
\hline
\end{tabular}

Escala (0-5) propuesta por (Webb y Kluver, 2014).

MAD: Miembro anterior derecho.

MAI: Miembro anterior izquierdo.

MPD: Miembro posterior derecho.

MPI: Miembro posterior izquierdo.

En el caso de la clasificación de la enfermedad por grupo etario, el grupo hembras servidas es el más afectado, como se había mencionado, las condiciones del lugar en donde se encontraban, pudo ser la causa principal de esta afectación, ya que la granja tiene bastantes problemas de encharcamiento en los potreros, donde normalmente están los animales pastando (Gráfica 1). 
Tabla 4. Análisis de la población ovina por categorías etarias (\%)

\begin{tabular}{cccc}
\hline Grupos & Sanos & Enfermos & Total \\
\hline Machos & 7.13 & 2.00 & 9.13 \\
Ovejas lactantes & 2.00 & 2.57 & 4.56 \\
Ovejas vacías & 19.96 & 2.47 & 22.43 \\
Ovejas servidas & 11.41 & 7.98 & 19.39 \\
Borregas & 8.46 & 4.09 & 12.55 \\
Destetos & 13.50 & 1.71 & 15.21 \\
Borregos & 6.18 & 0.29 & 6.46 \\
Ovejas secas & 8.94 & 1.33 & 10.27 \\
Total & 77.57 & 22.43 & 100.00 \\
\hline
\end{tabular}

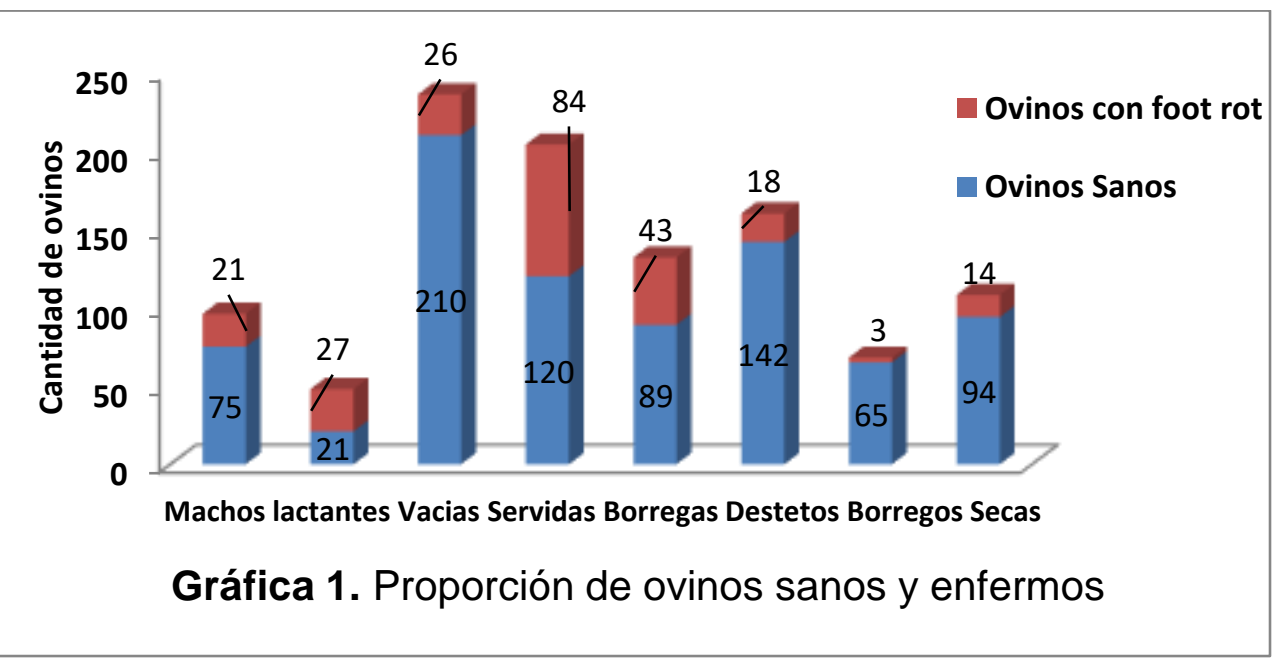

En la inspección de los ovinos de la granja, se observó que el $80.08 \%$ de la población afectada tiene el grado más leve de pododermatits interdigtal según esquema de clasificación propuesto por Webb y Kluver, (2014), el 1.69\% mostró grado $3 b$, y el $4.66 \%$ presentó un grado cuatro (Tabla 5 ), teniendo en cuenta que las condiciones ambientales de la producción pueden ser factores predisponentes 
para la presentación de la enfermedad, se deben atenuar mediante un manejo especifico y constante para cada caso en particular, porque si la enfermedad avanza, puede llegar a condiciones patológicas severas, con el consecuente aumento de la población afectada, lo cual se refleja en pérdidas productivas y por ende económicas, por lo tanto es recomendable que ante la presentación de algún grado pododermatitis interdigital, inclusive si es leve, se comience con un plan preventivo o curativo según sea el caso, para evitar la propagación de la enfermedad al resto de la población.

Tabla 5. Pododermatitis interdigital en la población de ovinos evaluados

\begin{tabular}{ccc}
\hline Grado de afección $^{*}$ & Ovinos afectados & Porcentaje (\%) \\
\hline 1 & 189 & 80.08 \\
2 & 8 & 3.39 \\
$3 a$ & 2 & 0.85 \\
$3 b$ & 4 & 1.69 \\
$3 c$ & 10 & 4.24 \\
4 & 12 & 5.08 \\
5 & 11 & 4.66 \\
Total & 236 & 100 \\
\hline
\end{tabular}

${ }^{*}$ Escala (1-5) propuesta por Webb y Kluver, (2014).

En el grupo sometido al experimento (16 ovinos), se evaluaron en total 64 pezuñas, las cuales fueron inspeccionadas antes y después del tratamiento, con el objetivo de evidenciar cambios observables de esta patología. De las 32 pezuñas de la raza criolla colombiana, el $40.7 \%$ están afectadas por algún grado de pododermatitis interdigital, y tan solo el $9.4 \%$ se encontraban sanas; mientras que en la raza Corriedale, de 32 pezuñas, el $34.3 \%$ se encontraban afectadas, frente a un $15.6 \%$ sanas, evidenciando que la raza criolla puede ser más susceptible a esta enfermedad (Tabla 6).

Cuando se clasifican los grados de pododermatitis interdigital, y el número de pezuñas afectadas en cada categoría, se encontró que el grado 3a presentó 15, y 
en uno 16 (Gráfico 2), indicando que la afección puede ir de una presentación leve hasta avanzar rápidamente a una clasificación 3a, o incluso más avanzado, aunque cabe destacar que depende en gran medida de los factores climáticos y la prevención o uso de pediluvios, puesto que se debe hacer de los mismos de manera preventiva, y más en épocas donde los animales son más susceptibles a daños e infecciones de las pezuñas; también se debe resaltar que esta clasificación se pudo realizar gracias a una observación meticulosa de las pezuñas, para determinar efectivamente el grado de la patología, según las características de cada grado de la enfermedad.

Tabla 6. Estado de las pezuñas del grupo de ovinos sometido al tratamiento

\begin{tabular}{cccccc}
\hline Raza & $\begin{array}{c}\text { Pezuñas } \\
\text { sanas }\end{array}$ & $\begin{array}{c}\text { Porcentaje } \\
(\%)\end{array}$ & $\begin{array}{c}\text { Pezuñas } \\
\text { afectadas }\end{array}$ & $\begin{array}{c}\text { Porcentaje } \\
(\%)\end{array}$ & Total \\
\hline Criolla & 6 & 9.4 & 26 & 40.7 & 32 \\
Corriedale & 10 & 15.6 & 22 & 34.3 & 32 \\
Total & 16 & 25 & 48 & 75 & 64 \\
\hline
\end{tabular}

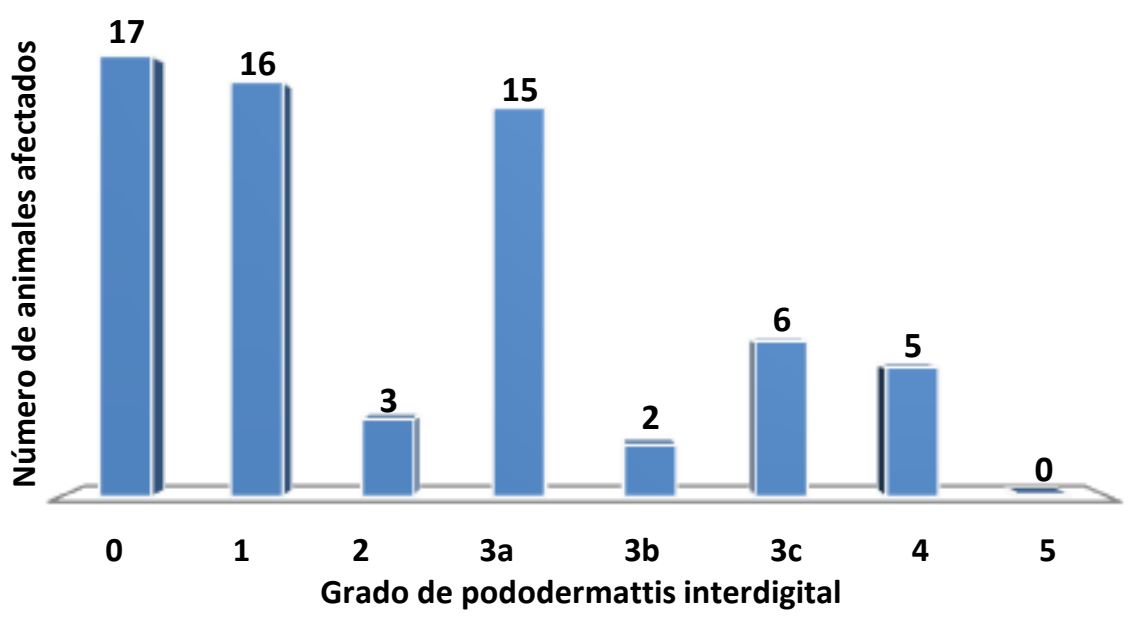

Gráfica 2. Grado de pododermatitis interdigital de las pezuñas de animales tratados

\section{Evidencia del pos tratamiento}

Las lesiones pódales fueron observadas mediante registro fotográfico antes y después de realizado el tratamiento, para comprobar que tan eficiente fue el 
pediluvio utilizado, y que porcentaje de recuperación se alcanzó. En algunos casos graves se observaron lesiones grado $3 \mathrm{c}$, es decir la pezuña rojiza con tejido necrótico de coloración verde-café, con parcial desprendimiento y destrucción del casco; después de aplicar el tratamiento, el cambio de la pezuña fue notable puesto que ya no presentaba exudado ni coloración rojiza, ni desprendimiento, además el tejido estaba sano en la almohadilla plantar (Figura 4).
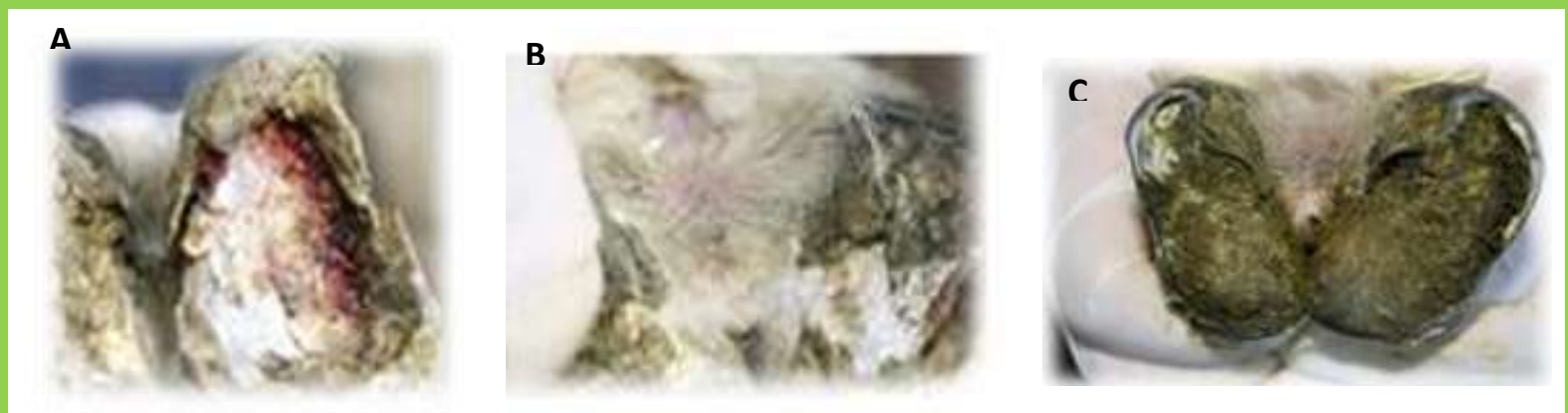

Figura 4. Evidencia antes (A y B) y después $(C)$ del tratamiento

En otro caso de un ovino con pododermatitis interdigital grado 3 se observó un tejido necrótico de coloración blanquecino, de aspecto duro, reseco, en el cual hubo daño de la queratina, además de presentar dermatitis interdigital. Cuando se aplicó el tratamiento, la pezuña, tuvo una reparación satisfactoria de la queratina, y a los pocos días ya no se evidenciaba el daño en la misma (Figura 5).
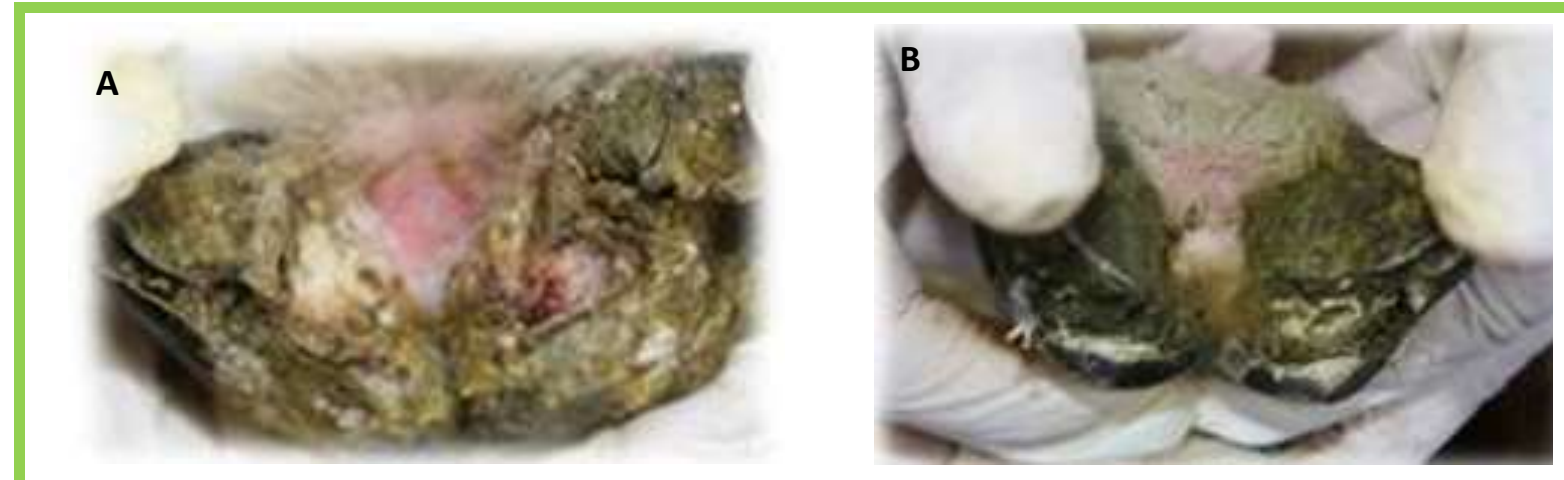

Figura 5. Evidencia antes $(A)$ y después $(B)$ del tratamiento 
En otro caso de pododermatitis pero grado 4, se observó una coloración rojiza del espacio interdigital, en la parte queratinizada de la pezuña se apreciaba una ulcera de color rojiza, con desprendimiento del casco, de coloración café oscuro. Se observó recuperación satisfactoria del tejido queratinizado y la parte interdigital por efecto del tratamiento, puesto que no presentó inflamación ni coloración rojiza posterior al mismo (Figura 6).

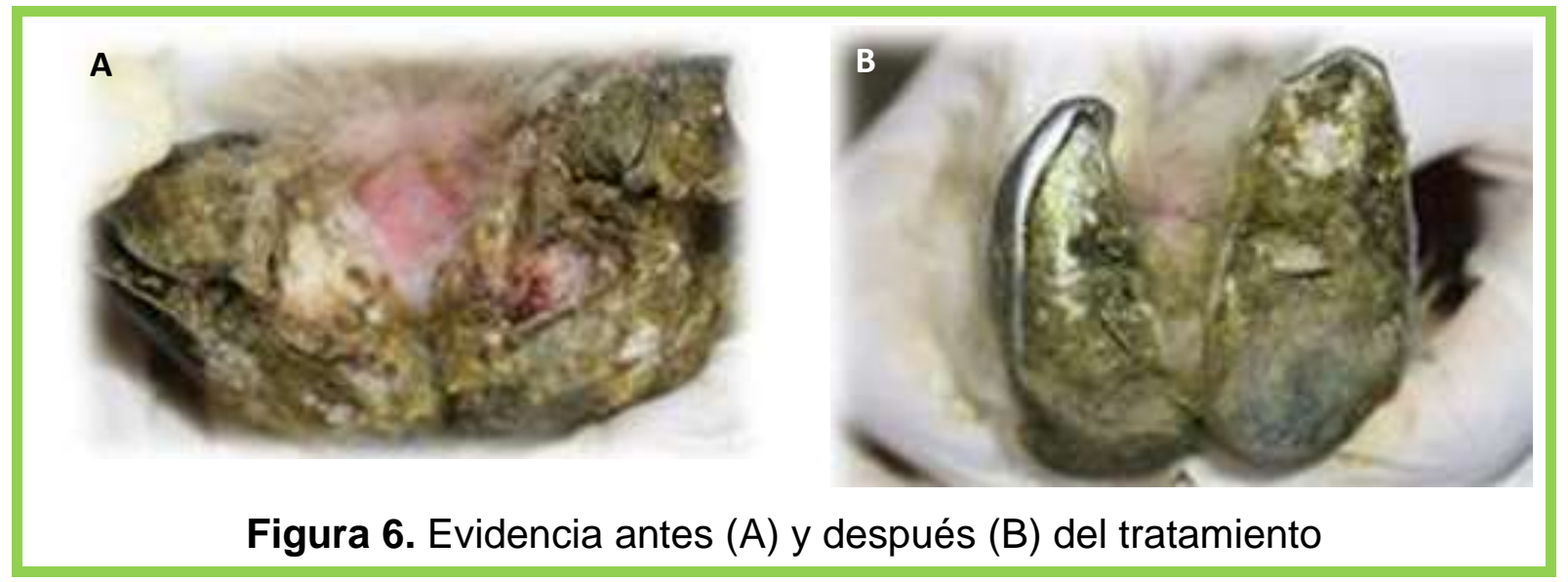

En otro caso de pododermatitis interdigital grado 4 se observó desprendimiento y perdida de la pezuña, con tejido necrótico y exudado de coloración café y negro, con daño interdigital; después del tratamiento, hubo formación de la queratina, y cierre de la laceración de la pezuña, tampoco se observó daño interdigital, el aspecto y sanidad de la pezuña mejoró evidentemente (Figura 7).
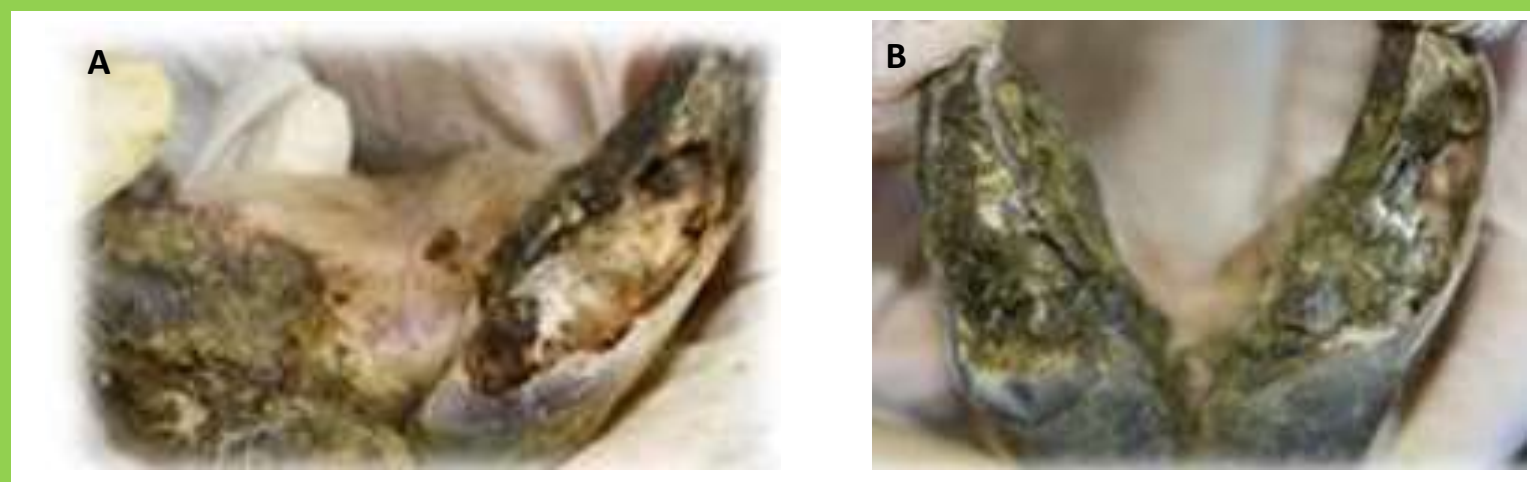

Figura 7. Evidencia antes $(A)$ y después $(B)$ del tratamiento 
Indudablemente los factores medioambientales afectan el desarrollo de esta enfermedad, estos casos de pododermatitis interdigital estudiados coinciden con las observaciones realizadas por Ferreira et al., (2002), puesto que el microorganismo Fusobacterium necrophorus actúa con mayor facilidad en una pezuña predispuesta, ablandada por la alta temperatura, además por el tipo de suelo que pisan, por el alto de las pasturas y la susceptibilidad racial e individual. Kimberling y Ellis, (1990) afirman que la humedad induce una hiperqueratosis de la sustancia córnea blanda en la unión córneo cutánea y causa un espesamiento y maceración de la piel interdigital, F. necrophorus logra colonizar las grietas del espacio interdigital causando focos de necrosis en los tejidos nobles, y en esos tejidos desvitalizados y con restos orgánicos, y gracias a un factor estimulante del crecimiento y protector, una exotoxina leucocídica que lo protege de la fagociosis, inicia su desarrollo Dichelobacter nodosus.

Wassink et al., (2010) confirman que estos microorganismos elaboran y secretan unas poderosas proteasas que digieren la elastina y la queratina de la pezuña y le permiten avanzar en anaerobiosis hacia las profundidades del corion solar y de la muralla, la invasión generalmente comienza en la parte posterior del espacio interdigital, en los talones, y se extiende hacia adelante por la cara interna de la muralla y por la suela. Fusobacterium produce su acción necrotizante y $D$. nodosus su acción proteolítica, lo que genera una gran inflamación de toda la pezuña, precisamente esto fue lo que se presentó en los ovinos que tenían pododermatitis interdigital grado tres y cuatro (Figuras 5 y 6 ).

Se concuerda con lo observado por Calderón et al., (2011) en lo referente a la prevención, puesto que es necesario un adecuado control sanitario en la granja, porque las afecciones pódales son una de las mayores preocupaciones de los productores, es por ello que al comprender la importancia de su epidemiología y fisiopatología, se pueden establecer estrategias preventivas que permitan mantener su control una vez afecto un rebaño. Sin embargo, aún hay mucho por investigar de esta enfermedad, puesto que rutinariamente no se realiza diagnóstico mediante aislamiento del $D$. nodosus patógeno gram negativo 
anaerobio que colabora en la evolución y propagación de la pododermatitis interdigital, tema de interés para continuar estudiando.

\section{CONCLUSIONES}

Los factores medio ambientales como la temperaturas, las lluvias y los encharcamientos de potreros facilitan la evolución de la pododermatitis interdigital, puesto que la bacteria Fusobacterium necrophorum es un microorganismo que hace parte de la flora gastrointestinal de los rumiantes y de otros animales, por lo tanto se presenta una constante eliminación al ambiente natural del rebaño, por lo tanto resulta prácticamente imposible erradicar la enfermedad, por ello es necesario controlar algunos factores para evitar su propagación.

El uso de pediluvios con sulfato de zinc al 10\% durante tres días obtuvo una efectividad del $97 \%$ en el control de las lesiones pódales, tal como se evidenció en el registro fotográfico post tratamiento, puesto que sólo dos pezuñas que representaron un $3.1 \%$ continuaban con lesiones leves.

\section{RECOMENDACIONES}

Para no entrar ni propagar la pododermatitis interdigital se recomienda que antes de comprar ovinos se compruebe que no presenten lesiones en las pezuñas; además realizar cuarentena de los animales que ingresan al rebaño, y para toda la población, arreglo de pezuñas con regularidad, uso de pediluvios, separación de animales sanos y enfermos, y descarte de animales con lesiones severas.

\section{REFERENCIAS BIBLIOGRÁFICAS}

1. Arévalo Á., Correa G. Tecnología en la ovinocultura colombiana: estado del arte. Revista Ciencia Animal. 6 125-142. 2013.

2. Bennett G.N. Dichelobacter nodosus and Fusobacterium necrophorum in ruminants with lameness and footrot, Doctor of Philosophy. Lincoln University, Nueva Zelanda. 231 p. 2011.

3. Calderón C., De la Barra R., Uribe H., Martínez M. Susceptibilidad a afecciones podales en ovejas de raza Chilota, Romney Marsh y Suffolk Down. En: XXXVI Congreso de la Sociedad Chilena de producción animal. Punta Arenas, Chile. 2011. 
4. Cederlöf S.E., Hansen T., Klaas I.C., Angen O. An evaluation of the ability of Dichelobacter nodosus to survive in soil. Acta Veterinaria Scandinavica. 55 (4): 14. 2013.

5. da Silva C. Lesões podais em ovinos na mesorregião sudoeste rio-grandense, Dissertação de mestrado. Programa de pós-graduação em ciência animal, Universidad Federal do Pampa, Uruguaiana, Brasil. 85 p. 2016.

6. Fernández M., E M., Serrano E. Pedero del ovino y caprino, Mundo ganadero, No 81, 46-50. 1996. Recuperado 15 Julio 2017. Disponible En: https://www.researchgate.net/profile/Emma Serrano/publication/28284375 Peder 0 del ovino y caprino/links/53fc72d00cf22f21c2f3d9a6/Pedero-del-ovino-ycaprino.pdf

7. Ferreira G., Mederos A., Bonino J., Casaretto A. Estimación de costo/beneficio en el control de Foot rot en Ovinos. INIA Serie FPTA-INIA. 7 33-41. 2002.

8. Ferrer L.M., Ramos J.J. Las cojeras en el ganado ovino: clínica y prevención. Servet, Zaragoza, España. 188 p. 2008.

9. Hernández L.G. Control de parasitismo gastrointestinal y problemas reproductivos en ovinos y caprinos: medidas para la temporada invernal. ICA, Bogotá, Colombia. 23 p. 2012.

10. Kennan R.M., Han X., Porter C.J., Rood J.I. The pathogenesis of ovine footrot. Veterinary microbiology. 153 (1-2): 59-66. 2011.

11. Kimberling C.V., Ellis R.P. Advances in the control of foot rot in sheep. The Veterinary clinics of North America. Food animal practice. 6 (3): 671-681. 1990.

12. Mederos A., Ferreira A.G., Montossi A.F., Bonino J., Casaretto A., Scremini P., Gil A., Estudios sobre footrot ovino en el Uruguay: Relevamiento de su prevalencia, evaluación de las pérdidas productivas y económicas. INIA Serie Actividades de Difusión, Montevideo, Uruguay. 22 p. 2001.

13. Muzafar M., Green L.E., Calvo L.A., Tichauer E., King H., James P., Wellington E. Survival of the ovine footrot pathogen Dichelobacter nodosus in different soils. Anaerobe. 38 (2016): 81-87. 2016.

14. Nascimento G.M., Oliveira A.C., Rodrigues T., Araújo J.R., Garino F., Vilar S., Riet F. Pododermatite infecciosa em ovinos e caprinos no sertão paraibano. Ciência Animal Brasileira. 585-590. 2009.

15. Ramos J.J., Ferrer L.M. La exploración clínica del ganado ovino y su entorno. Servet, Zaragoza. 422 p. 2007.

16. Wassink G.J., King E.M., Grogono-Thomas R., Brown J., Moore L.J., Green L.E. A within farm clinical trial to compare two treatments (parenteral antibacterials and hoof trimming) for sheep lame with footrot. Preventive veterinary medicine. 96 (12): 93-103. 2010.

17. Webb J., Kluver P. Footrot manual for contractors, 30. 2014. Recuperado 13 Julio 2017. Disponible En: http://www.lbn.org.au/wp-content/uploads/2015/12/Footrotmanual-for-footrot-contractors.pdf

18. Winter A.C. Treatment and control of hoof disorders in sheep and goats. Veterinary Clinics: Food Animal Practice. 27 (1): 187-192. 2011.

19. Witcomb L.A., Green L.E., Calvo L.A., Russell C.L., Smith E.M., Grogono R., Wellington E. First study of pathogen load and localisation of ovine footrot using fluorescence in situ hybridisation (FISH). Veterinary microbiology. 176 (3-4): 321 327. 2015. 